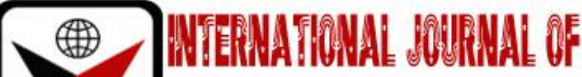

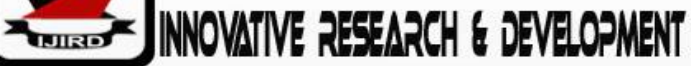

ISSN 2278 - 0211 (Online)

\section{Leadership as a Panacea for Delivery of Successful Community Development Projects for Community Growth}

\begin{tabular}{c} 
Sophy Awuor Okeyo \\
Student, Department of Open and Distance Learning (ODEL), \\
University of Nairobi, Kenya \\
Dr Lillian Otieno Omutoko \\
Senior Lecturer, Department of Open and Distance Learning (ODEL), \\
University of Nairobi, Kenya \\
\hline
\end{tabular}

\begin{abstract}
:
Community development projects are initiated in communities to respond to socio - economic needs. Community development has faced a myriad of challenges such as lack of project goal attainment.

Purpose: The purpose of this study was to examine how leadership influences delivery of successful community development projects in Thika Sub County Kiambu County Kenya.

Methodology: The study employed descriptive survey and correlation research designs. Purposive and stratified sampling techniques were used to select the study participants. The sample size was 143 and the response rate was 91.6\%. Data was analyzed using descriptive and inferential statistics.

Findings: The study findings revealed that in the absence of leadership or when leadership is held constant at zero, community development projects would fail with a constant $=(-1.020)$. The regression model predicted up to $78.2 \%$ of variations in delivery of community development projects and the major factors that contribute to delivery of successful community development projects are leadership styles and skills.

Unique Contribution to the Theory, Practice and Policy: The study concludes and recommends that multiple leadership skills are significant in improving the success of projects and that transformational leadership inspires project teams to focus on goals and achieve project objectives which benefit communities and spur community growth.
\end{abstract}

Keywords: Community, community development, leadership, needs, projects

\section{Introduction}

Community development is accepted as an approach that is vital in promoting socio- economic development of communities. Community participation is pertinent for successful project delivery which in turn steers development. This approach promotes skills transfer to community members and provides an opportunity for them to participate constructively by making key project decisions and management of project funds. The rationale behind this thinking is spelt out in Community Driven Development (CDD) chapter in the World Bank's poverty reduction strategy paper (PRSP) Sourcebook (Dongier, 2003) which postulates that CDD as a mechanism to change can speed up the pace of change through increases participation of community members in their own development, enhance bottom up approach to change and enable supplementation of the limited public resources with locally available resources to ensure efficiency, equity, relevance and sustainability of development projects through empowerment.

Community driven development approach was espoused in order to promote efficiency, effectiveness and success of community development initiatives however, skeptics have raised a plethora of pitfalls related to CDD especially during the project implementation process. The pitfalls include inadequate stakeholder involvement and sometimes it is not clear whether a feasibility study was conducted to determine the project's viability before resource allocation. Other concerns include poor contract negotiations, exploitation of limited resourceswhile in other cases, the projects are run as brief cased organizations without clear vision and mission leading to lack of project goal attainment. Summers (2001) for instance show some discontent with the World Bank's duty in steering community development initiatives under the consortium of such projects. He argues that such projects can lead to structures that undermine constitutionally appointed leaders. Harriss, Platteau and Abraham (2001) on the other hand identify the concerns that emerge when certain ideas like 'Community, Empowerment and Capacity for Collective Action' are converted into large projects on strict time lines. In such circumstances, they argue that leaders with vested interests may resolve to implement projects with outcomes that are easier to measure as opposed to complex ones with more strict timelines a situation that may compromise the entire project success. To help bring local communities into action, it is vital to provide effective leadership since oftenly resources are scarce thus require a mastery of effective practical actions to convert the limited resources into beneficial projects to spur community growth and sustainability. 


\section{Problem Statement}

Community development projects (CDPs) have increased in the recent past with most development workers targeting to work directly with communities (Salome, 2017). A study of Southern African community based projects conducted by Harley (2003) stated that undemocratic practices such as poor governance and leadership, inadequate leadership skills, lack of transparency and accountability have contributed to unsuccessful delivery of community projects. It is argued that a lot of evidence presented in support of the direct link between leadership and delivery of successful projects is anecdotal and oftenly over emphasized on the 'transformational' role of leaders in project success (Quick, 1992; Simms, 1997). The limited or inconclusive nature of research findings in this area suggested the need to investigate further on the link between leadership and delivery of successful projects and this study was a step in this direction. According to (Kouzes and Posner 2007), leadership that guides motivates and influences followers to make better decisions thus results to project success. In Thika Sub County,CDPs lack accountability, feasibility studies are not conducted and in some cases, leaders can't be separated from the projects a situation that has contributed to the mushrooming of brief cased projects that do not meet their set objectives. The multiple factors associated with poor implementation and massive failure of community projects in Thika Sub County created a gap in establishing the critical factors that contributes to the failure which this study intended to assess with a sharp focus on leadership. When effective leadership is provided, people participate voluntarily to accomplish the outlined project goals and objectives for project success which in turn leads to community growth and project sustainability.

\section{Objective of the Study}

The objective of the study was to determine how leadership influences delivery of successful community development projects for community growth.

\section{Literature Review}

Communities are often the target of projects that focus on improvement of livelihoods and local level development. Best practice demands that feasibility studies are conducted to identify the needs that communities have and quite often development initiatives target vulnerable groups on the basis of basic needs such as infrastructure, agriculture and even health. These projects are intended to improve livelihoods and in African countries there are numerous initiatives that are located in informal settlements and rural areas to respond to these needs. The residents of these localities are often vulnerable groups with different levels of vulnerability which demands ethical considerations to prevent exploitation and enhance activities that will contribute positively. Vulnerable groups are categorized as people who are economically disadvantaged, terminally ill, women and children whose ability to make informed decisions as to what is best for them due to the low education levels and socio economic status may be low according to (Omutoko, 2017). Community development initiatives are thus significant in promoting bottom up approach to change while involving vulnerable populations who are often the target of such initiatives at the driver's seat. As an approach to development projects, United Nations Development Programmes (2016) views community development as initiativeswhere people's efforts are united with those of the implementing agencies, government authorities, funding partners, and other relevant stakeholders to improve the social and economic status of vulnerable group of people at the grass root level. According to Fakoya (1984), community development provides a platform where people at the community level organize themselves to identify problems affecting them and plan for action to solve the identified problems by implementing the developed plans. Mukunga and Omutoko (2012) on the other hand argue that communities need to be empowered so as to actively participate in development projects. Findings from their study on 'Influence of community participation on the performance of Kiserian Dam water project Kajiado County' determined that lack of community empowerment results to low participation which in turn leads to projects that are not sustained'. They further suggested that project implementing agencies must accept the challenge for project sustainability and carry the whole community along while leaders must be rightfully accountable and answerable to project beneficiaries. Ugal (1992) for instance discovered that CDP's were not properly organized, were in effective in performance, made decisions in isolation and did not maximize on the resources at their disposal. He further argued that CDP's in river state constructed educational and health facilities without involving the government along with them thus the projects remained idle without personnel and equipment from appropriate authorities. For projects to be successfully implemented, a thorough feasibility study is required through effective leadership to determine whether a project is technically, legally and economically feasible. This helps in determining whether a project is worth the investment or not and also helps to establish the potential for project success and any risks the project is likely to face so that risk mitigation measures are put in place to eliminate or reduce the risk implications.

It can therefore be argued that for any community development initiative to be successful, effective leadership is essential. Studies on the link between leadership and project success have been conducted and debates on one best way to lead emerged. Of particular significance is the interest pegged on charismatic leadership, which oftenly is referred to as transformational leadership (Bass and Avolio, 1993). A number of studies make the assumption that transformational leadership is linked to delivery of successful projects (Howell and Avolio, 1993). Conceptually, there are claims that the visionary and inspirational skills of transformational leaders motivate followers to deliver successful performance (Nicholls, 1988; Quick, 1992). Other studies across the globe have presented findings that effective leadership should create a plat form where guidelines are clearly communicated from the beginning to the end of a project and support is given to team members to meet their set goals by tracking their progress throughout the project implementation process. Hanson (2015) views leadership as the ability to guide others without force into a direction or decision that leaves them feeling empowered and accomplished. Hersey, (2001) on the other hand posits that leadership is the process of influencing activities of an individual or a group in efforts toward goal accomplishment. He further argues that the essence 
of leadership is achieving project objectivesin a team spirit. It could however be argued that the influence and mobilization is of little essence in project context unless the ultimate goal is attained according to the shared aspirations for leadership to be viewed as successful. This statement is in agreement with Drucker (2004), who believed that leadership is about results. The world today is evolving and becoming more competitive thus requires a very different kind of leadership from what was studied in the past (Koech and Namusonge, 2012). While leaders in the past perhaps managed complex organizations, this was a world of relative stability and predictability. Today's globalized world has organizations coping with rapidly changing environments thus require a totally different set of leadership styles, skills and experiences to face the new reality which includes; working in flexible contexts connected by real-time electronic communication and increasingly mobile employees who have become the critical resource of their projects according to (Koech and Namusonge, 2012).

The world today requires leaders with multiple set of skills in order to become change agents and centers of gravity that keep internal focus and enable people and projects to adapt and be successful (Alimo and Metcalfe, 1998). Furnham (2002) assert that the appropriate measurement outcome from leadership quality is the leader's efficacy in achieving project objectives, goals and staff needs in their job. The measure of delivery of successful projects in this study is represented by the degree to which community development projects are able to achieve theirgoals and objectives effectively and efficiently. Fayes, (1994) reported that services will not meet the quality promised unless there is effective leadership that works at all levels to achieve project goals. This article did not discuss what effective leadership is but rather portrayed that leadership is important in attainment of set goals thus the need to conduct more research in this area to determine what effective leadership is in promoting project success. Fiedler (1996) for instance provided impetus on the significance of leadership by arguing that the major determinant of the success or failure of a group, organization, or even an entire country is dependent on effective leadership. It has been argued that projects have sought to cope with the rising volatility and turbulence of the external environment by training and developing leaders to acquire the right skills to cope with the changing environments (Hennessey, 1998). This means that the link between leadership and project success requires a critical review and this study is a step to this direction.

\section{Research Methodology}

Descriptive survey and correlation research designs were adopted for the study which enabled the researcher to describe data as it was without manipulation while the relationship between leadership and delivery of successful CDPs was determined through correlation research design. The target population was 38 registered nonprofit community development projects in Thika Sub County from 2016 - 2018. The sample frame was 38 registered CDP's in Thika Sub County. Simple random sampling technique was used to select the 11 actual CDPs that were included in the study in accordance with Mugenda and Mugenda (1999) who argues that $30 \%$ of the total or accessible population is representative. Out of the 11 selected CDPs, a project manager, M\&E officer, project officer, finance officer and 3 government officials were selected purposively to give a total of 47 respondents. The other respondents included project beneficiaries who were selected using stratified sampling where Yamane (1967) sample size formula was employed from a total population of 165,301 project beneficiaries to give a representative sample of 96 project beneficiaries as follows;

Where; $\mathrm{n}=\mathrm{N}$

$\mathrm{N}$ - Population

$$
1+\overline{N(e) 2}
$$

$\mathrm{n}$ - Sample size

e - Margin of error $10 \%(0.1)$

Confidence level used for sampling - 95\% Z $\quad$ score - 1.96

Calculation of the sample size

$\mathrm{n}=165,301$

$1+\overline{165,301(0.1) 2}$

$\mathrm{n}=96$

The sample size therefore included 44 project staff, 3 government officials and 96 project beneficiaries which gave a representative sample of 143 respondents who participated in the study. Data collection was done through structured questionnaires which consisted of open and closed ended questions where the respondents recorded their answers. A likart scale was adopted in some instances of closed ended questions to report the degree of assessment on the topic under study. Prior to the actual data collection, a pretest on the questionnaire was done to test validity and reliability of the data collection instrument where $10 \%$ of the sample size equivalent to 14 respondents who had similar characteristics as those in the study area in Juja were involved as recommended by Mugenda and Mugenda, (2003). This helped the researcher to make any necessary changes in the questionnaire or rephrase questions in order to avoid ambiguity and determine protocol to be followed prior to the main study. To further ensure content validity, this research specified the domain of indicators which were relevant to the topic under study while construct validity was determined by ascertaining that the scores from the instrument gave correct inferences. Reliability of the research instrument for the study was established through Cronbach's Alpha which measures internal consistency. The acceptable coefficient was 0.7 and above because it is a commonly accepted rule of thumb that indicates acceptable reliability according to Mugenda (2003). Cronbach's alpha reduces time required to compute a reliability coefficient (Mugenda \& Mugenda, 2003). Constructs that had a reliability coefficient $<0.7$ were deleted and replaced to ensure that a higher reliability coefficient was attained.The findings for Cronbach's Alpha reliability test were established as follows; 


\begin{tabular}{|c|c|c|}
\hline Variables & Reliability & Cronbach's Alpha Comments \\
\hline Leadership & 0.727 & Accepted \\
\hline $\begin{array}{c}\text { Performance of CDPs in Thika } \\
\text { Sub County }\end{array}$ & 0.721 & Accepted \\
\hline
\end{tabular}

Table 1: Reliability of Research Instrument

Findings on table 1 show reliability of constructs. Nunnally (1978) established the alpha value at 0.7 which this study used to bench mark against. From the findings, all the constructs had reliability $>0.7$ which shows a high reliability.

\section{Discussion of Findings}

The researcher collected data from a total of 143 respondents who consisted of project managers, project officers, finance officers, M\&E officers, project beneficiaries and government officials. Questionnaires were sent to all the 143 respondents out of which 131 were returned to the researcher representing a response rate of $91.6 \%$. This response rate was considered adequate for analysis based on the assertions by Mugenda and Mugenda (2003) that a response rate of $60 \%$ is good while $70 \%$ and above is excellent. Out of 143 respondents, 44 were project staff where male were $68.8 \%$ while female were $31.3 \%$. This implied that senior positions among CDPs in Thika Sub County were still dominated by men which defeat the efforts of gender mainstreaming among leadership positions. Project beneficiaries were 96 where males were $36.5 \%$ while female were $63.5 \%$ which indicated that CDPs targeted more female project beneficiaries since they believe in creating more impact through women compared to men.

The study made various assumptions during statistical tests to ensure that findings derived empirical evidence to draw meaningful conclusions and recommendations. The study findings revealed that leadership styles and leadership skills were the major factors that influenced delivery of projects successfully. Leaders with multiple skills were found to be the most effective in delivering projects successfully. These arguments are in line with Kaverenge (2015) who argued that different skill mixes are required at different managerial levels with conceptual skills required more at a higher level while technical skills are require at a lower level. The study also established that best practice demands that a feasibility study is conducted to identify community needs so as to channel resources to match needs and project viability to improve socio economic status of communities and spur their growth. The study findings are further illustrated in the table below.

\begin{tabular}{|c|c|c|c|c|}
\hline Statements related to leadership & Min & Max & Mean & Std. Deviation \\
\hline $\begin{array}{l}\text { The manager encourages team to be creative and to look at } \\
\text { issues from different view points }\end{array}$ & 4.00 & 5.00 & 4.8 & .397 \\
\hline $\begin{array}{c}\text { The manager is a good role model who inspires and mentors } \\
\text { the team }\end{array}$ & 4.00 & 5.00 & 4.8 & .420 \\
\hline $\begin{array}{c}\text { The manager displays power and confidence in management of } \\
\text { the project }\end{array}$ & 4.00 & 5.00 & 4.7 & .471 \\
\hline $\begin{array}{l}\text { The manager appreciates different abilities and provides } \\
\text { individualized attention to staff }\end{array}$ & 3.00 & 5.00 & 4.6 & .554 \\
\hline $\begin{array}{l}\text { The skills and trainings have contributed to better } \\
\text { management of the project }\end{array}$ & 3.00 & 5.00 & 4.5 & .567 \\
\hline $\begin{array}{l}\text { The manager is able to differentiate different staff abilities and } \\
\text { assign tasks accordingly }\end{array}$ & 2.00 & 5.00 & 4.2 & .644 \\
\hline $\begin{array}{l}\text { The manager capacity builds staff on important tasks and } \\
\text { schedules in the project. }\end{array}$ & 3.00 & 5.00 & 4.2 & .628 \\
\hline The manager consults and involves staff in decision making & 2.00 & 5.00 & 4.1 & .660 \\
\hline Certain level of experience is required in management of CDPs & 1.00 & 5.00 & 4.0 & 1.107 \\
\hline Data Source: Field Data & & & & \\
\hline
\end{tabular}

Findings on table 2 ranks the perception of respondents on the influence of leadership in delivery of successful community development projects in Thika Sub County and indicates that the most influential factor in delivery of successful CDPs with regards to leadership was that managers should be good role models who inspires and mentors team supported with a mean of 4.8 and standard deviation of 0.420 . This was followed by the perception that managers should encourage staff to be creative and to look at issues from different viewpoints. This implies that visionary and inspirational skills of transformational leaders motivate followers to deliver superior performance translated in the overall success of an organization. Respondent's perception that certain level of experience is required in delivery of successful CDPs had the least mean of 4.0 and standard deviation of 1.107 which implies that experience level does not seem to be very influential in delivery of successful projects.

Rating respondents' views on the extent to which leadership experience influenced delivery of successful projects, 93.7\% cumulatively felt that leadership experience did not seem to influence the success of CDP. These findings contradict Kaverenge (2015) whose findings revealed that leadership experience influenced the success of IT projects. On the other hand, $96.9 \%$ of the respondents cumulatively agreed to a great extent that leadership styles and skills influenced delivery of successful CDPs. These arguments concur with Zenger and Folkman (2002) whose findings established that a combination of leadership skills seemed to be more powerful predictors of project effectiveness and success. A study by 
(Mc Grath and Mac Millan 2000), also revealed that there is a significant relationship between leadership style and projects success which support this study findings.

\begin{tabular}{|c|c|c|c|c|c|}
\hline Type of skills & Conceptual & Technical & Human & $\begin{array}{c}\text { All of the } \\
\text { above }\end{array}$ & Total \\
\hline Frequency & 1 & 8 & 3 & 20 & 32 \\
\hline Percentage & $3.1 \%$ & $25.0 \%$ & $9.5 \%$ & $62.5 \%$ & $100 \%$ \\
\hline
\end{tabular}

Table 3: Leadership Skills and Delivery of Successful Community Development Projects Data Source: Field Data

Table 3 revels that conceptual, human and technical skills are all important in delivery of successful projects represented by $62.5 \%$ while $3.1 \%$ of the study respondents felt that only conceptual skills were important. This implies that for effective project success, a manager needs technical, conceptual and human skills. The study can therefore deduce that the major factors in leadership that influence delivery of successful projects are leadership styles and leadership skills. The findings are also in line with Kaverenge (2015) whose findings revealed that leaders with strength in multiple skills are the most effective. She further argued that, conceptual skills are more effective at higher levels while technical skills are more effective at lower levels.

\subsection{Regression Analysis}

To further determine the relationship between leadership and delivery of successful projects, the study adopted inferential statistics where linear regression analysis was adopted. The regression analysis used ordinary least square method (OLS) of estimation to extract the line of best fit. As a pre estimation diagnosis, the data set was subjected to assumption of regression in terms of normality, linearity and homoscedasticity tests without any major violations observed. The study proceeded to test the estimated model as follows; $Y=\beta_{0}+\beta_{1} X_{1}+\varepsilon_{i}$

In this model; $Y$ was delivery of successful CDPs, $\beta_{0}$ was a constant in the regression model that shows success level of CDPs in the absence of the independent variable (leadership), $\beta_{1}$ was beta coefficient of the independent variable, $X_{1}$ was leadership, $\varepsilon_{\mathrm{i}}$ was error term associated with regression model. The model generated a model summery, Analysis of variance, and coefficient table. The study also tested the following hypothesis to determine the relationship between leadership and successful delivery of community development projects.

- $\mathrm{H}_{01}$ : Leadership has no significant influence in delivery of successful community development projects.

\begin{tabular}{|c|c|c|c|c|c|c|c|c|c|}
\hline Model & \multirow{2}{*}{$\mathbf{R}$} & R Square & Adjusted & \multirow{2}{*}{$\begin{array}{c}\text { Std. Error of } \\
\text { the Estimate }\end{array}$} & & & & \multicolumn{4}{|c|}{ Change Statistics } \\
\cline { 5 - 9 } & & & & & $\begin{array}{c}\text { R Square } \\
\text { Change }\end{array}$ & $\begin{array}{c}\text { F } \\
\text { Change }\end{array}$ & df1 & df2 & Sig. F \\
Change
\end{tabular}

Table 4: Model Summery

a. Predictors: (Constant), Leadership

The model summary outcome shows the coefficient of determination $\left(\mathrm{R}^{2}\right)$, which measures how well the resulting model is likely to predict the dependent future outcomes. The model summery shows the relationship between leadership and delivery of successful projects and indicates that it hada high value of coefficient of determination, where $\mathrm{R}^{2}=0.782$. This meant that the model could predict up to $78.2 \%$ of the variations in the success of CDPs and hence provided a good fit. The implication was that $21.8 \%$ of the changes in the success of CDPs could be attributed to or accounted for by other factors not presented in this model.

\begin{tabular}{|l|c|c|c|c|c|c|}
\hline \multicolumn{2}{|c|}{ Model } & Sum of Squares & df & Mean Square & F & Sig. \\
\hline \multirow{3}{*}{1} & Regression & 18.770 & 4 & 4.692 & 24.223 & $.000^{\mathrm{e}}$ \\
\cline { 2 - 7 } & Residual & 5.230 & 27 & .194 & & \\
\cline { 2 - 7 } & Total & 24.000 & 31 & & & \\
\hline
\end{tabular}

Table 5: Analysis of variance - ANOVA

a. Dependent Variable: Delivery of Successful Community Development Projects

b. Predictor: (Constant), Leadership

The ANOVA Table 5 was used to interpret the significance of the models. It shows that the model had a p-value = 0.000 (p-value $<0.05$ ) at $95 \%$ confidence level which meant that the model was significant in predicting the linear relationship between the predictor (leadership) and delivery of successful CDPs. This imply that the modelwas generally statistically significant thus was adopted for the study. 


\begin{tabular}{|c|c|c|c|c|c|c|c|c|}
\hline & \multirow[t]{2}{*}{ Model } & \multicolumn{2}{|c|}{$\begin{array}{l}\text { Unstandardized } \\
\text { Coefficients }\end{array}$} & \multirow{2}{*}{$\begin{array}{c}\begin{array}{c}\text { Standardized } \\
\text { Coefficients }\end{array} \\
\text { Beta }\end{array}$} & \multirow[t]{2}{*}{$\mathbf{t}$} & \multirow[t]{2}{*}{ Sig. } & \multicolumn{2}{|c|}{$\begin{array}{c}95.0 \% \\
\text { Confidence } \\
\text { Interval for B } \\
\end{array}$} \\
\hline & & B & Std. Error & & & & $\begin{array}{l}\text { Lower } \\
\text { Bound }\end{array}$ & $\begin{array}{l}\text { Upper } \\
\text { Bound }\end{array}$ \\
\hline \multirow[t]{2}{*}{1} & (Constant) & -1.020 & 1.397 & & -.730 & .472 & -3.885 & 1.846 \\
\hline & Leadership & -.456 & .224 & -.198 & -2.038 & .051 & -.915 & .003 \\
\hline
\end{tabular}

Table 6: Regression Coefficients

a. Dependent Variable: Delivery of Successful Community Development Projects

The regression coefficient model was derived from the formular;

$\mathrm{Y}=-1.020+-0.456 \mathrm{X}_{1+\varepsilon_{\mathrm{i}}}$

The model provided a good fit thus its coefficients were interpreted. From the fitted equation; Y stood for delivery of successful projects, $\mathrm{X}_{1}$ was leadership. The results indicate that in the absence of leadership (independent variable at zero or constant) CDPs (projects) would fail or have a negative performance as shown by the constant $(-1.020)$. The results further imply that a unit change in leadership style would results to $45.6 \%$ negative change in CDPs performance implying that poor leadership styles significantly influence project outcomes. Findings on Table 6 further revealed that, the calculated value for the independent variable was < than the critical value $(0.05)$ at $95 \%$ confidence level thus the results were interpreted that leadership had a significant coefficient where $\mathrm{p}$-value $=0.05$. The study therefore rejected $\mathrm{H}_{01}$ at $5 \%$ level of significanceand interpreted the results to mean that leadership has a significant influence on delivery of successful community development projects in Thika Sub County.

\section{Conclusion}

The study concludes that leadership styles and skillshave a key role to playin delivery of successful projects for community growth. Leadership experience did not seem to play a major role in project success. Multiple leadership skills are thus significant in improving project success and transformational leadership style inspires and motivates project teams to focus on goal and objectives attainment which benefit communities and spur community growth and project sustainability.

\section{Recommendations}

Due to the complex nature of CDPs the study recommends that project leaders and managers should acquire multiple leadership skills such as technical, human and conceptual which should be applied at various levels in order to enhance effective project outcomes for community growth. Emphasis should also be pegged on transformational leadership style since it is seen as a viable source of management development and sustained competitive advantage.

\section{References}

i. Akande, R. (2016). The impact of education on living standards in Nigeria. Internal Journal of Development and Management review, Vol 11 June, Pg. 1 - 2

ii. Alimo-Metcalfe, B. (1998). Effective Leadership. Interim report on Local Government Management Board. Unpublished.

iii. Berry, D. (2013). The importance of executive leadership in creating a post merged organizational culture conducive to effective performance management; SA Journal of Human Resource Management. Vol. 3, No. 1, Pg. 4776.

iv. Bass, BM. and Avalio, BJ. (1993). Transformational leadership and organization culture, Public Administration Quarterly, 17(1): 112 - 17

v. Cooper, R. D. \& Schindler, S.P (2014). Business. Research Methods. Boston: Irwin McGraw Hill.

vi. Drucker, P. (1968). Management, Task, Responsibility and Practice: New York Press

vii. Fiedler, F. E. (1996). Leadership in Gibb, C.A. (Ed). A new model, Leadership Baltimore, Mary Land: Penguin Books.

viii. Harley, A. (2003). Report on a survey of CBO's in Southern Africa, Center for Adult Education, University of Kwazulu Natal.

ix. Hennessey, J.T. (1998). Reinventing Government: Does Leadership Make the Difference?Public Administration Review, 58(6): 522-32.

x. Kiambu County Integrated Development Plan (2017). https://www.kiambu.go.ke

xi. Kothari, C.R. (2006). Research Methodology. $2^{\text {nd }}$ Edition, New Age International Publishers, New Delhi.

xii. Koech, P.M \& Namusonge, G.S. (2012). Effects of leadership styles on organizational performance at state corporations in Kenya. International journal of Business and commerce, Vol 2, No 1: Sep 2012.

xiii. Luvai, K. T. (2012). Factors influencing the effectiveness of community based organizations in Kibwezi District Kenya. University of Nairobi.

xiv. McGrath, GB, \& MacMillan, 1. C (2000). Entrepreneurial mindset: strategies for continuously creating opportunities in an age of uncertainty. Harvard School of Business.

xv. Mkutu, A. (2012). The role of community based organizations in the development of rural areas. A case study of community based organizations in Kiogoro division Kisii County. St Paul's University Kenya. 
xvi. Mugenda, O. M., and Mugenda, A.G. (2003). Research Methods: Quantitative and Approaches, Nairobi: Act Press.

xvii. Mukunga, F. M \& Omutoko, L.O (2012). Influence of community participation on the performance of Kiserian Dam water project, Kajiado County Kenya. University of Nairobi Kenya

xviii. Mwaura, M. \&Karanja, N. (2014). Factors affecting performance of community based organization projects in Kenya. Jommo Kenyatta University of Agriculture and Technology, Kenya

xix. Nicholls, J. (1988). The Transforming Autocrat, Management Today, March: 114-18.

xx. Nunnally, J.C. (1978). Psychometric theory. $2^{\text {nd }}$ Edition, McGraw - Hill

xxi. Omutoko, L.O. (2017). Ethical considerations and research with vulnerable groups. Retrieved from https://youtu.be/fYEyTsH8vGk. Retrieved on Feb 242017

xxii. Quick, J.C. (1992). Crafting an organization culture: Herbs Hand at South west Airline, organizational dynamics, 21 (2); $45-56$

xxiii. Salome, M. (2017). Factors influencing performance of community development projects: A case of Inades Formation Kenya (African Institute of social and economic development) In Machakos County Kenya. University of Nairobi Kenya.

xxiv. Turner, R. (2017). Five Necessary Conditions for project success. International journal of project management, $349-350$.

xxv. United Nations Development Programme. (2016). A new sustainable Development Agenda. Retrieved March 20, 2016, From United Nations Development Programme: undp.org

xxvi. Zenger, J. H, \& Folkman, J. (2002). The extraordinary leader. Turning good managers in to great leaders. New York: Mc Graw - Hill Companies, Inc

xxvii. Zhu, W, Chew, I.K H \& Spangler, W.D. (2005). CEO Transformational leadership and organizational outcomes. The Mediating role of Human Capital Enhancing Human Resource Management. The leadership Quarterly, Vol 6, No 1 pp $39-5$ 